\title{
Canadians expect easier online access to health care: CMA survey
}

\author{
n Cite as: CMAJ 2019 August 26;191:E952. doi: 10.1503/cmaj.109-5809
}

Posted on cmajnews.com on August 9, 2019; updated on August 15, 2019.

M ost Canadians expect better online access to health care in the next decade, according to an Ipsos poll conducted for the Canadian Medical Association (CMA). However, many remain concerned about the privacy and privatization of virtual care.

The survey's 2005 participants were divided on whether the health system will improve, worsen or stay the same in the next 10 years. But those who were optimistic cited advancing technology and innovation as the main reasons. "Today, we've become accustomed to doing almost everything online. And Canadians are clear: they want the same when it comes to managing their health," Dr. Gigi Osler (CMA past-president) said in a press release.

Most of the survey participants expect technology will help health providers see more patients, reduce administrative burden and improve health outcomes in the next decade. More than three-quarters expect to be able to track appointments and access their complete medical history online. Three in five expect that data from wearable devices will be linked to their health records and everything about their health - from blood work to sleeping patterns - will be monitored through a centralized platform.

Most survey participants were optimistic that virtual care will lead to improved access, more timely care, greater convenience and better overall health care. More than 4 in 10 said they are willing to

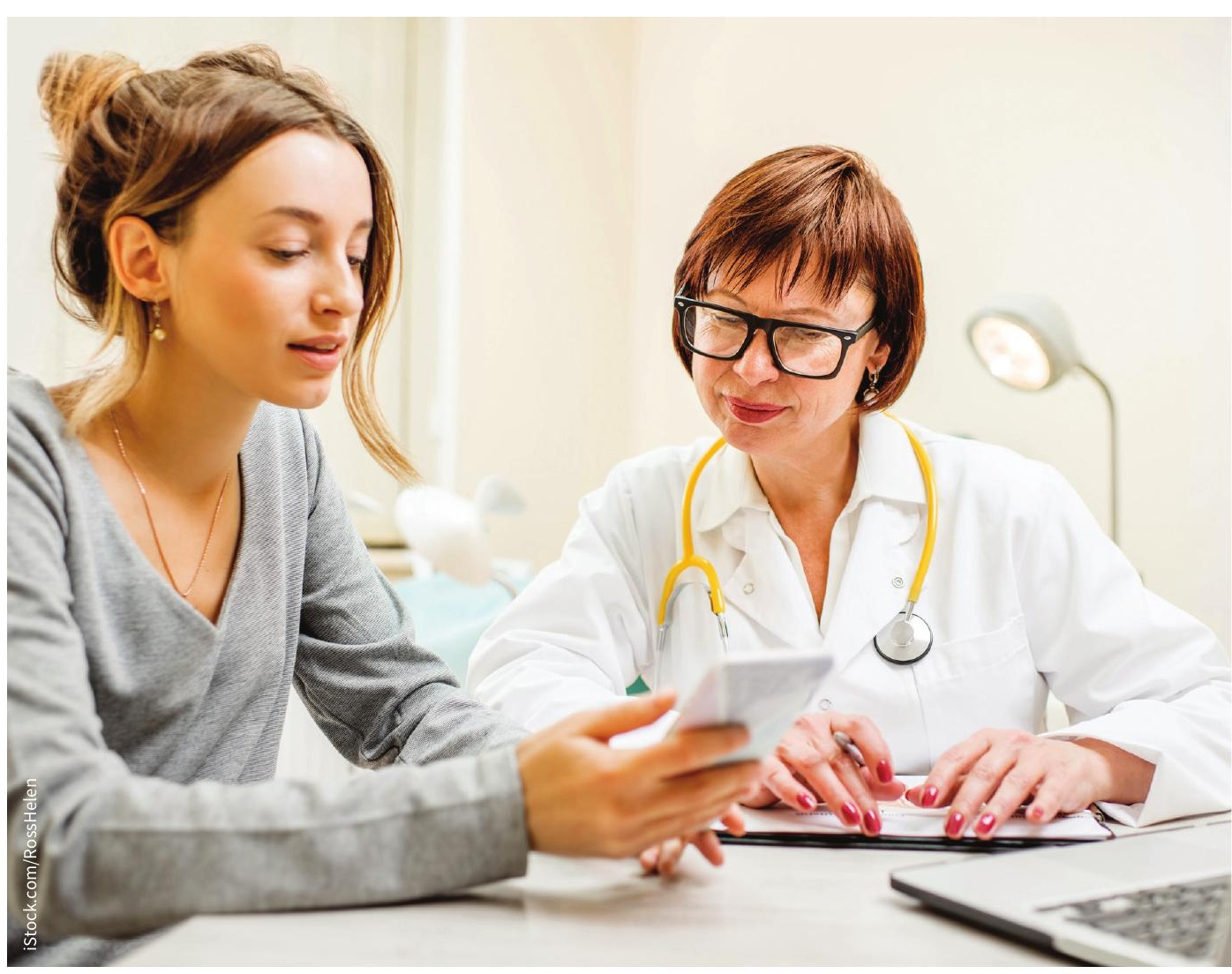

More than three-quarters of Canadians say they expect online access to their full medical history within the next decade.

share health data with programs like Google, Alexa, Siri and Fitbit, and would allow those programs to monitor and report issues to health providers.

Three-quarters of those polled expressed concern about losing human connection and compassion as more care goes virtual. Most also worry that virtual care will put their privacy at risk or open the door to privatization of health care. More than half expressed concerns about who will access their data, who will own it, and the risk of being hacked. Nearly all believe they should have full ownership of their health data and should be able to choose who gets access.

Ipsos conducted the poll between June 26 and July 2. Physicians from across Canada gathered in Toronto in August to discuss how to create a more connected health system at the 2019 CMA Health Summit.

Lauren Vogel, CMAJ 